\title{
On The Oxidation Resistance of Nickel-Based Superalloys
}

\author{
Atsushi Sato ${ }^{1, a}$, Johan J Moverare ${ }^{2, b}$, Magnus Hasselqvist ${ }^{2, c}$ \\ and Roger C Reed ${ }^{1, d}$ \\ ${ }^{1}$ Depertment of Metallurgy and Materials, University of Birmingham, U.K. \\ ${ }^{2}$ Finspång, Siemens Industrial Turbomachinery $A B$, Sweden \\ aaxs756@bham.ac.uk, bjohan.moverare@siemens.com, 'cmagnus.hasselqvist@siemens.com, \\ r.c.reed@bham.ac.uk
}

Key words: Nickel alloys, Oxidation, Oxide, Thermodynamics, Segregation

\begin{abstract}
In this paper, the factors influencing the oxidation resistance of superalloys are studied. A model is proposed by which the $\mathrm{Al}_{2} \mathrm{O}_{3}$-forming properties of a given composition can be estimated, based upon the thermodynamic and kinetic factors influencing scale growth. The numerical modelling is tested by experimental work on a number of compositional variants of the newly-developed SCA425+ superalloy, which contains appreciable quantities of Cr. The modelling is shown to be in broad agreement with experiment. The effects of $\mathrm{Al}, \mathrm{Cr}$ and $\mathrm{Si}$ on the oxidation resistance of this class of alloy have been rationalised.
\end{abstract}

\section{Introduction}

Most existing nickel-based superalloys have been designed for aeroengine applications; experience has shown that they are not ideal for use in industrial gas turbines (IGTs) of the type used for power generation, on account of their inadequate resistance to environmental degradation. An accurate model which allows the oxidation resistance of nickel-based superalloys to be estimated as a function of their chemical composition would be extremely useful, but it has yet to be achieved. In this paper, the performance of three nickel-based single crystal superalloys are considered; these are prototypes which might find future application in the industrial gas turbines used for electricity generation. Whilst these alloys are shown to be $\mathrm{Al}_{2} \mathrm{O}_{3}$ formers, they are marginally so and this has allowed the factors influencing $\mathrm{Al}_{2} \mathrm{O}_{3}$ formation to be studied in detail.

\section{Experimental procedures}

Casting and Heat treatment. The prototype nickel-based single crystal superalloy SCA425+ was chosen for the present work. This a candidate for future application in industrial gas turbines partly on account of its $\mathrm{Cr}$ content (15.5 wt.\%) which is appreciably greater than for most other single crystal alloys - many of which were designed for aeroengine applications. Two derivatives of SCA425+ containing 0.25 and 0.5 wt.\% $\mathrm{Si}$ are also studied here; it has been reported that $\mathrm{Si}$ is beneficial with regard to $\mathrm{Al}_{2} \mathrm{O}_{3}$ layer formation [1-3], but one purpose of the experimentation was to check this for the SCA425+ alloy. The nominal compositions of the three alloys investigated are given in Table 1.

An industrial scale investment casting facility at the University of Birmingham was used to prepare single crystal castings in the form of $15 \mathrm{~mm}$ diameter rods of length $150 \mathrm{~mm}$. Typically,

Table1 Nominal compositions ([wt.\% ], Ni-bal) of superalloys investigated.

\begin{tabular}{lllllllll}
\hline & Co & Cr & Mo & W & Al & Ta & Hf & Si \\
\hline SCA425+ & 5.0 & 15.5 & 1.0 & 4.0 & 4.55 & 8.0 & 0.1 & - \\
\hline SCA425+0.25Si & 5.0 & 15.5 & 1.0 & 4.0 & 4.55 & 8.0 & 0.1 & 0.25 \\
\hline SCA425+0.5Si & 5.0 & 15.5 & 1.0 & 4.0 & 4.55 & 8.0 & 0.1 & 0.5 \\
\hline
\end{tabular}


three rods were cast in each run with a withdrawal speed of $\sim 200 \mathrm{~mm}$ per hour; the anticipated temperature gradient was $7.5^{\circ} \mathrm{C} / \mathrm{mm}$. Ceramic moulds were prepared from alumina, silica and zircon in the usual way; the final mould thickness was $\sim 6 \mathrm{~mm}$. These were de-waxed in a steam autoclave for 5 mins and then sintered at $1000^{\circ} \mathrm{C}$ for an hour in air, prior to casting. The casting stock was melted by Ross \& Catherall in Sheffield, UK to industry-leading standards. Chemical analysis indicated less than $7.2 \mathrm{ppmw}$ of sulfur in the stock, so that - since the oxidation temperatures used here are $1000^{\circ} \mathrm{C}$ or lower and the tests carried out isothermally - any influence of this element on oxidation performance will be negligible [4]. Casting was carried out under a vacuum of better than $10^{-4} \mathrm{~Pa}$. The single crystal bars were carefully removed from the mould, and then sand blasted. In order to confirm whether the cast bar contains any grain defect, the bars were macro etched using $\mathrm{HCl}+5 \sim 10$ vol. $\% \mathrm{H}_{2} \mathrm{O}_{2}$ solution. No freckles were observed. Subsequently, the castings were heat treated to remove chemical heterogeneity inherited from the processing, and to develop appropriate precipitate morphologies. The solution treatment chosen for SCA425+ was $1280^{\circ} \mathrm{C} 1$ hour $\rightarrow 1300^{\circ} \mathrm{C} 5$ hours, followed by air-cooling; for SCA425+0.25Si, it was $1260^{\circ} \mathrm{C} 1$ hour $\rightarrow 1280^{\circ} \mathrm{C} 5$ hours, followed by air-cooling; for $\mathrm{SCA} 425+0.5 \mathrm{Si}$, it was $1230^{\circ} \mathrm{C} 1$ hour $\rightarrow 1250^{\circ} \mathrm{C} 5$ hours, followed by air-cooling. The first and second aging treatments for all alloys were $1120^{\circ} \mathrm{C} 24$ hours and $850^{\circ} \mathrm{C} 20$ hours followed by air-cooling, respectively.

Oxidation test. $2 \mathrm{~mm}$ thick discs were sliced from the heat-treated castings, polished to $0.05 \mu \mathrm{m}$ alumina and cleaned, and then placed in an $\mathrm{Al}_{2} \mathrm{O}_{3}$ boat before being exposed isothermally at $900^{\circ} \mathrm{C}$, $950^{\circ} \mathrm{C}$ and $1000^{\circ} \mathrm{C}$ for 100 hours, respectively. The oxidized surfaces were subjected to X-ray diffraction (XRD) analysis. Cross-sections of these samples were analysed using back-scattered electron (BSE) imaging in a scanning electron microscope (SEM) equipped with energy dispersive X-ray spectroscopy (EDX).

Modelling. In order to predict the growth rate of $\mathrm{Al}_{2} \mathrm{O}_{3}$ on any given Ni-base superalloy, separate thermodynamic and kinetic factors are proposed. The details will be discussed elsewhere [5], but briefly the oxidation rate of n-type $\mathrm{Al}_{2} \mathrm{O}_{3}, k_{t}$, can be estimated according to

$$
k_{t} \propto\left\lfloor\sum_{n=i}\left(z_{i}-z_{\mathrm{Al}}\right) c_{i}^{\gamma}\right\rfloor \cdot \Delta G_{f}
$$

where $z_{i}$ is the valence of element $i$ 's ion: for examples, when $i=\mathrm{Ni}$, then $z_{\mathrm{Ni}}=$ (valence of $\mathrm{Ni}$ in the most stable nickel oxide, $\mathrm{NiO})=2$ and $z_{\mathrm{Al}}$ is the valence of $\mathrm{Al}$ ion $=3$. $c_{i}^{\gamma}$ represents the atomic fraction of element $i$ in the $\gamma$ phase at the oxidation temperature. Thus the square brackets term in Eq. 1 represents total effective valence in $\mathrm{Al}_{2} \mathrm{O}_{3}\left(\mathrm{Val}_{t}^{\text {eff }}\right)$. Here, $\Delta G_{f}$ is the Gibbs free energy of formation of the $\mathrm{Al}_{2} \mathrm{O}_{3}$ oxide and this can be expanded consistent with the Van't Hoff isotherm [6, 7] according to

$$
\Delta G_{f}=\Delta G_{0}+R T \ln \left(\frac{a_{\mathrm{Al}_{2} \mathrm{O}_{3}}^{2 / 3}}{a_{\mathrm{Al}}^{4 / 3} \cdot P_{\mathrm{O}_{2}}}\right)
$$

where $\Delta G_{0}$ is the standard free energy of formation per $1 \mathrm{~mol}$ of $\mathrm{O}_{2}$, which can be calculated as $0.2193 \times T-1127.3137 \mathrm{~kJ} / \mathrm{mol}$ [8], $T$ is absolute temperature and $R$ is the gas constant. The activity of the oxide of $\mathrm{Al}$ is represented by $a_{\mathrm{Al}_{2} \mathrm{O}_{3}}$ (this is commonly taken to be unity) and $a_{\mathrm{Al}}$ is the activity of $\mathrm{Al}$ in the nickel-base superalloy which is subject to oxidation. The partial pressure of oxygen is $P_{\mathrm{O}_{2}}$ which is $0.21 \mathrm{~atm}$ in one of atmosphere air.

\section{Results and Discussion}

Isothermal Oxidation Testing. In Fig.1, SEM micrographs of the oxidized superalloys are shown after exposure at temperatures of $900^{\circ} \mathrm{C}, 950^{\circ} \mathrm{C}$ and $1000^{\circ} \mathrm{C}$ for 100 hours. The EDX analysis (Fig.2) revealed that the darkest oxide layer in Fig.1 consisted mainly of aluminium and oxygen, consistent with $\alpha-\mathrm{Al}_{2} \mathrm{O}_{3}$; the presence of this phase was confirmed by XRD. One can see from Fig.1 
that there is a tendency for $\alpha-\mathrm{Al}_{2} \mathrm{O}_{3}$ to form a continuous layer only at higher Si contents and when the exposure temperature is higher; at lower temperatures and in the absence of $\mathrm{Si}$, internal oxidation is prevalent. Additionally, the presence of $\mathrm{Ta}_{2} \mathrm{O}_{5} / \mathrm{NiTa}_{2} \mathrm{O}_{6}$ and $\mathrm{Cr}_{2} \mathrm{O}_{3}$ were confirmed by both EDX and XRD. For example, it was found that $\mathrm{Ta}_{2} \mathrm{O}_{5}$ is the brightest oxide and $\mathrm{Cr}_{2} \mathrm{O}_{3}$ is the second brightest oxide for SCA425+ exposed to $1000^{\circ} \mathrm{C}$, and $\mathrm{NiTa}_{2} \mathrm{O}_{6}$ is the brightest oxide and $\mathrm{Cr}_{2} \mathrm{O}_{3}$ is the second brightest oxide for the same alloy at $900^{\circ} \mathrm{C}$. Thus, as one moves outward across the scale towards the outer surface, one moves from $\mathrm{Al}_{2} \mathrm{O}_{3} \rightarrow \mathrm{Ta}_{2} \mathrm{O}_{5} / \mathrm{NiTa}_{2} \mathrm{O}_{6} \rightarrow \mathrm{Cr}_{2} \mathrm{O}_{3}$. $\mathrm{A}$ continuous $\mathrm{Al}_{2} \mathrm{O}_{3}$ layer is prevalent at higher temperature and when $\mathrm{Si}$ is added.

Fig. 3 indicates the thicknesses of $\mathrm{Al}_{2} \mathrm{O}_{3}, \mathrm{Ta}_{2} \mathrm{O}_{5}$ and $\mathrm{Cr}_{2} \mathrm{O}_{3}$ with respect to the $\mathrm{Si}$ content in the alloys exposed at $1000^{\circ} \mathrm{C}$ for 100 hours. No significant changes in the thickness of $\mathrm{Al}_{2} \mathrm{O}_{3}$ were observed with respect to $\mathrm{Si}$ content. On the contrary, the more $\mathrm{Si}$ is added, the thinner $\mathrm{Cr}_{2} \mathrm{O}_{3}$ and $\mathrm{Ta}_{2} \mathrm{O}_{5}$ become. Furthermore, it is obvious from Fig. 1 that the $\mathrm{Al}_{2} \mathrm{O}_{3}$ sub-scale becomes a perfect $\mathrm{Al}_{2} \mathrm{O}_{3}$ layer with $\mathrm{Si}$ addition. This implies quicker decreases of $P_{\mathrm{O}_{2}}$ at $\mathrm{Ta}_{2} \mathrm{O}_{5} / \mathrm{Al}_{2} \mathrm{O}_{3}$ interface when $\mathrm{Si}$ is present. In other words, $\mathrm{Si}$ promotes the formation of a protective $\mathrm{Al}_{2} \mathrm{O}_{3}$ layer.
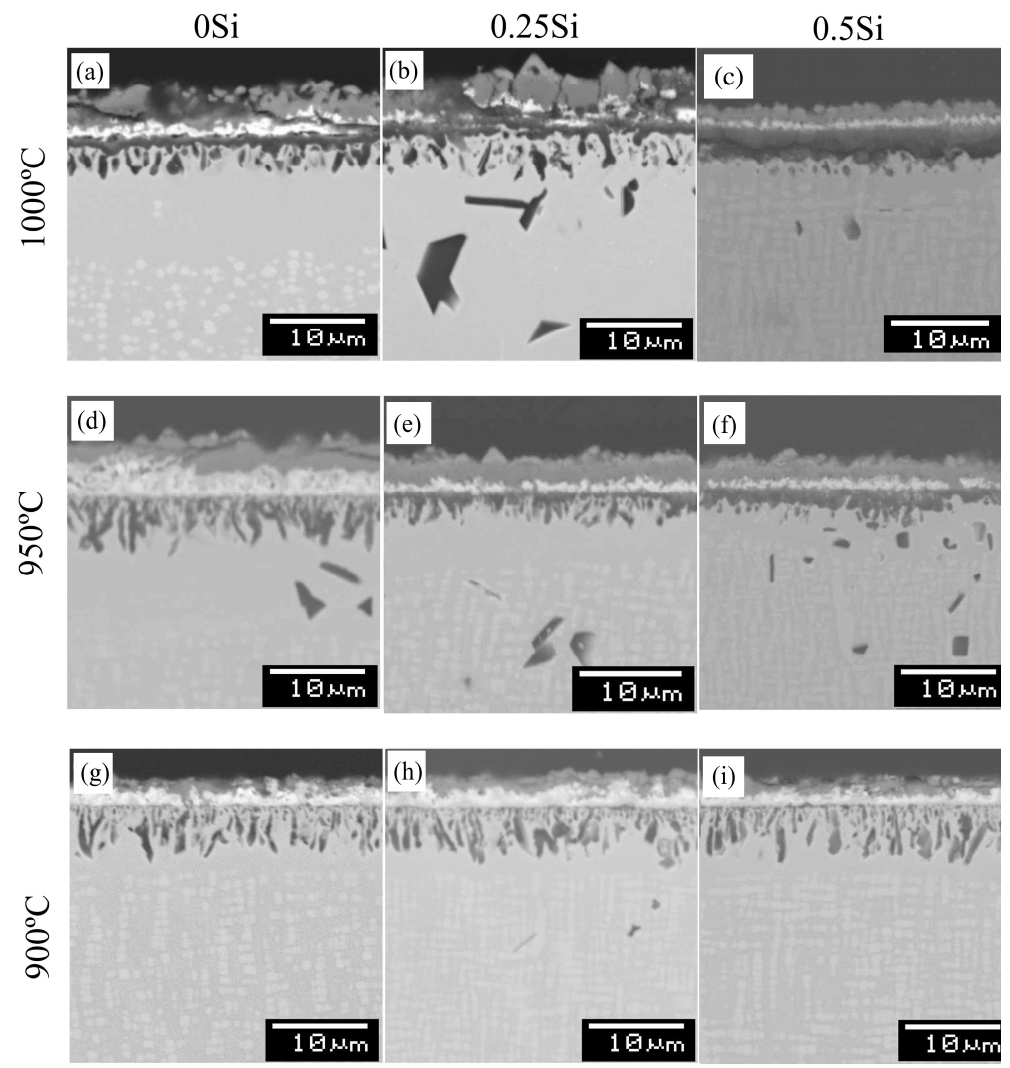

Fig.1 Micrographs of cross-sectioned superalloys after 100 hours exposure in one atmosphere air. Note that all micrographs were obtained from the dendrite core region of matrix.

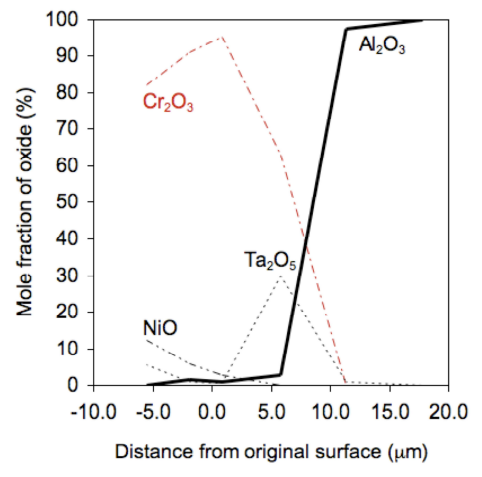

Fig.2 SEM-EDX result of Fig.1(a) stoichiometrically.

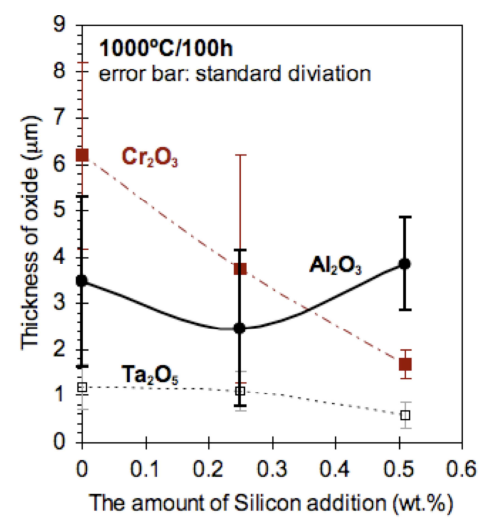

Fig.3 Summary of thickness of oxides in Fig.1 (a), (b) and (c).

Microsegregation Analysis. In order to rationalise the oxidation behaviour of the various chemical composition, microsegregation in the matrix was analyzed through the dendrite structure. Even when $\mathrm{Si}$ is added, $\mathrm{SCA} 425+$ could not form a continuous $\mathrm{Al}_{2} \mathrm{O}_{3}$ layer at $900^{\circ} \mathrm{C}$, see Fig. 1 ; therefore rougher-surfaced (120 grit) [9] longer-exposed samples were used for this purpose. By simultaneously analyzing both (i) from where the $\mathrm{Al}_{2} \mathrm{O}_{3}$ becomes continuous/discontinuous, and (ii) how much difference exists in the chemical composition through the dendrite structure, Fig. 4 was prepared. The chemical compositions of superalloys were analyzed at about $100 \mu \mathrm{m}$ inwards from metal/oxide interface along the [001] direction to avoid the effect of oxidation. The chemical composition in Fig. 4 indicates the average composition over about $300 \mu \mathrm{m}^{2}$. As the dendrites were 
tilted, these angles were measured by using BSE image contrast, and used geometrically to calibrate
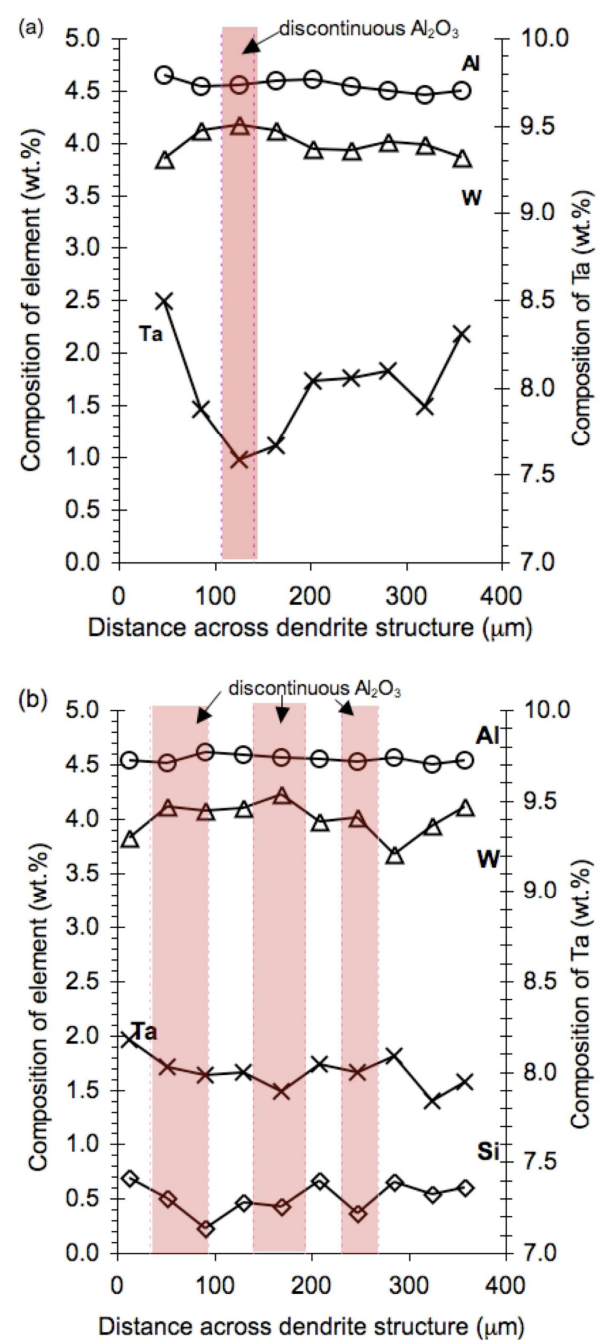

Fig.4 Microsegregations in matrix and $\mathrm{Al}_{2} \mathrm{O}_{3}$ morphologies at surface of (a) SCA425+ exposed at $1000^{\circ} \mathrm{C}$ for 300 hours, and

$\mathrm{SCA} 425+0.5 \mathrm{Si}$ exposed at $900^{\circ} \mathrm{C}$ for 300 hours.
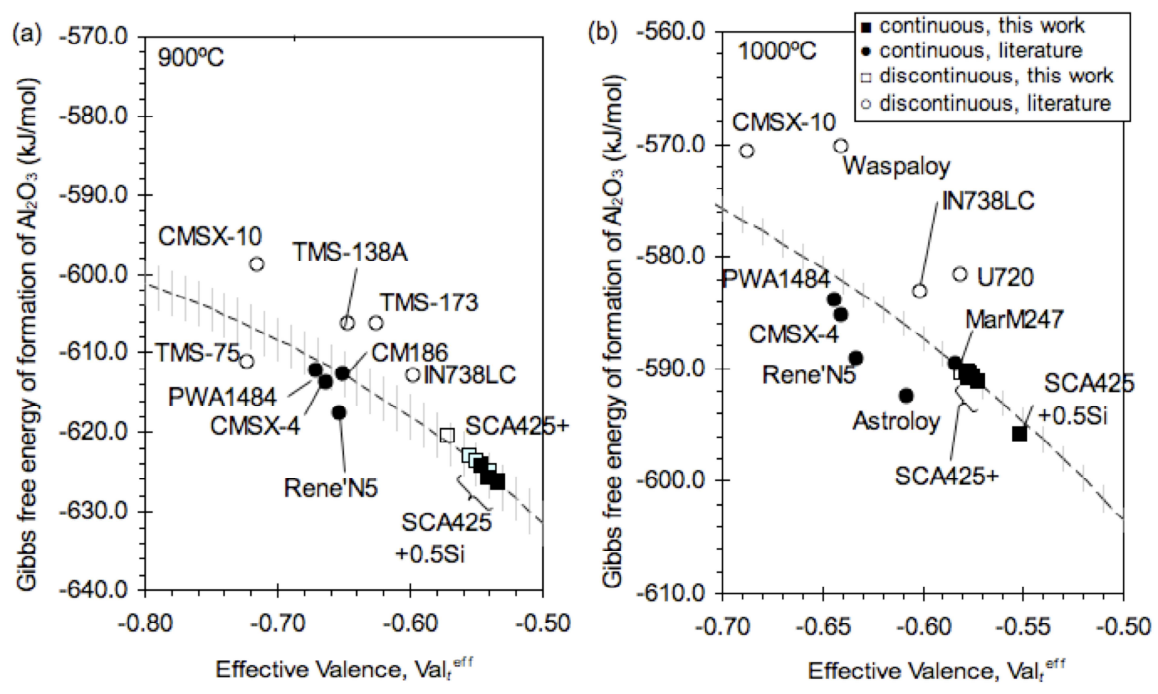
next chapter. position Fig 4 represents the relationship between the composition difference due to microsegregation and $\mathrm{Al}_{2} \mathrm{O}_{3}$ morphology. It is obvious from Fig.4a that the discontinuous $\mathrm{Al}_{2} \mathrm{O}_{3}$ preferentially formed at dendrite core region due to the microsegregation of $\mathrm{W}$ and Ta. Note that these compositions will be used for modelling in the

Oxidation diagram. Inspired by the form of Eq.1, socalled oxidation diagrams can now be developed. As will be seen, these have some power for the prediction of oxidation performance and therefore are useful for alloy design purposes. Fig 5 represents the oxidation diagram calculated from the microsegregation result above; on the $\mathrm{x}$ - and y-axes are plotted estimates of $\mathrm{Val}_{t}^{\text {eff }}$ and $\Delta G_{f}$, respectively. Alloys which form $\mathrm{Al}_{2} \mathrm{O}_{3}$ readily are expected to lie towards the bottom left of the diagrams; those for which a continuous $\mathrm{Al}_{2} \mathrm{O}_{3}$ scale is unlikely towards the top right. Since the performance of SCA425+ has been shown to be marginal with regard to continuous $\mathrm{Al}_{2} \mathrm{O}_{3}$ scale formation, its composition can be used to calibrate Eq. 1 and thus to identify the location of a critical isocontour; the isocontours tend asymptotically to the two axes owing to its hyperbolic nature, but in practice it has been found that the curvature is rather gentle in the calculated regimes of interest. These have been done for the temperatures $900^{\circ} \mathrm{C}$ and $1000^{\circ} \mathrm{C}$ on the diagrams given in Fig 5. Thus the calculated line which is plotted passes through the point for SCA425+. Fig.5 also contains the calculated results of some well-known superalloys chemical compositions are given in [10] - for which the oxide morphologies have been reported in the literature [10-15]. Note that there is some subjectivity involved in deciding whether any given alloy does indeed form a continuous layer of $\mathrm{Al}_{2} \mathrm{O}_{3}$, owing to the different practices used in the oxidation testing and the details reported; however one can see that the alloys which perform adequately tend to lie below the calculated line, and those not performing well lie above it. The sole discrepancy

Fig.5 The thresholds of $\mathrm{Al}_{2} \mathrm{O}_{3}$ layer formation at (a) $900^{\circ} \mathrm{C}$ and (b) $1000^{\circ} \mathrm{C}$ in terms of Gibbs free energy of $\mathrm{Al}_{2} \mathrm{O}_{3}$ formation and total effective valence in $\mathrm{Al}_{2} \mathrm{O}_{3}$ index. Comparisons from the literatures [10-15]. 
found concerns the result for the TMS-75 alloy exposed at $900^{\circ} \mathrm{C}$ for 100 hours. Our calculation predicted that TMS-75 is capable to form a continuous $\mathrm{Al}_{2} \mathrm{O}_{3}$, but report [14] indicates that it cannot, and reasons for this might be as follows. It is known that in the early (transient) stages of oxidation - before the steady-state is reached - a continuous layer of $\mathrm{Al}_{2} \mathrm{O}_{3}$ might not yet have become established. Furthermore, our attention has been restricted to the formation of n-type $\mathrm{Al}_{2} \mathrm{O}_{3}$, so that the cations are assumed to move more slowly than the anions. This is not necessarily the case for the transient $\theta-\mathrm{Al}_{2} \mathrm{O}_{3}$ which can form in these systems at early stages [16].

The model can be used to estimate the sensitivity of continuous alumina scale formation to the chemical composition of any given superalloy in the following way. Starting with the baseline composition of SCA425+ consistent with the emphasis of this paper, calculations of $\Delta G_{f}$ and $\mathrm{Val}_{t}^{\text {eff }}$ have been made after systematically altering the mean chemical composition by 1 at. $\%$ for each of the important alloying additions. The results can depicted on the oxidation diagrams, with vectors identifying the changes in position of the alloy with respect to the critical isocontour for continuous $\mathrm{Al}_{2} \mathrm{O}_{3}$ formation. Our predictions are as follows, see Fig.6. First of all, in general, the additions of $\mathrm{Al}$ and $\mathrm{Si}$ are beneficial to form $\mathrm{Al}_{2} \mathrm{O}_{3}$ layer. Secondly, $\mathrm{Cr}, \mathrm{Re}$ and $\mathrm{Co}$ are slightly beneficial or neutral. On the contrary, the addition of $\mathrm{W}, \mathrm{Ta}, \mathrm{Nb}, \mathrm{Ru}, \mathrm{Ti}$ and $\mathrm{Mo}$ are considered to be detrimental.

It can also be noticed from Fig. 6 that $\mathrm{Si}$ addition and $\mathrm{Al}$ addition has very similar vectors. First of all, both $\mathrm{Al}$ and $\mathrm{Si}$ have similar beneficial effect on SCA425+ thermodynamically: +1at.\%Al decrease $\Delta G_{f}$ from $-620.45 \mathrm{~kJ} / \mathrm{mol}$ to $-624.91 \mathrm{~kJ} / \mathrm{mol}$ and +1 at. $\%$ Si to $-624.99 \mathrm{~kJ} / \mathrm{mol}$. Thus, there is little difference in $\mathrm{y}$ - axes between +1 at. $\% \mathrm{Al}$ and +1 at. $\% \mathrm{Si}$ in Fig.6. In order to understand the small difference in $\mathrm{x}$ - axes between them, the factor influencing total effective valence of SCA425+ alloy are summarised in Fig.7. Here, adding higher valence element $\left(\mathrm{Si}^{4+}\right.$ etc...) and/or removing lower valence element $\left(\mathrm{Ni}^{2+}\right.$ etc...) from matrix increase total effective valence in $\mathrm{Al}_{2} \mathrm{O}_{3}$. Note that increasing effective valence is detrimental. In $\mathrm{Al}$ addition in Fig.7, there is a significant increase of the total effective valence due to the increases of volume fraction of $\gamma$ ' phase (Vf). This is because increasing Vf causes the reduction of Ni content from both $\gamma / \gamma^{\prime}$ phase (Again, Ni has the valence of positive 2 in $\mathrm{NiO}$ ). In $\mathrm{Si}$ addition, there is also a small effect of $\mathrm{Vf}$ increase, but this effect is much smaller than that of $\mathrm{Al}$ addition above. Instead, there is a significant effect of adding higher valence element, as $\mathrm{Si}$ has the valence of positive 4 in $\mathrm{SiO}_{2}$. Therefore, despite the fact that $\mathrm{Si}$ has the valence of positive 4, as Si addition does not significantly increase Vf than $\mathrm{Al}$ addition, both $\mathrm{Al}$ and $\mathrm{Si}$ shows similar effect on total effective valence in $\mathrm{Al}_{2} \mathrm{O}_{3}$ in Fig.6.

\section{Summary}

The SCA425+ single crystal superalloy is an alumina-former but only marginally so; higher oxidation temperatures and additions of $\mathrm{Si}$ promote the formation of a continuous layer of alumina. When estimates are made for effective valence and the thermodynamic driving force for the formation of $\mathrm{Al}_{2} \mathrm{O}_{3}$, the concept of an oxidation diagram can be used to predict whether any given alloy is likely to be an $\alpha-\mathrm{Al}_{2} \mathrm{O}_{3}$ former. It can be considered that $\mathrm{Si}$ addition is similarly beneficial like $\mathrm{Al}$ addition due to its positive thermodynamical effect and less increase of Vf.

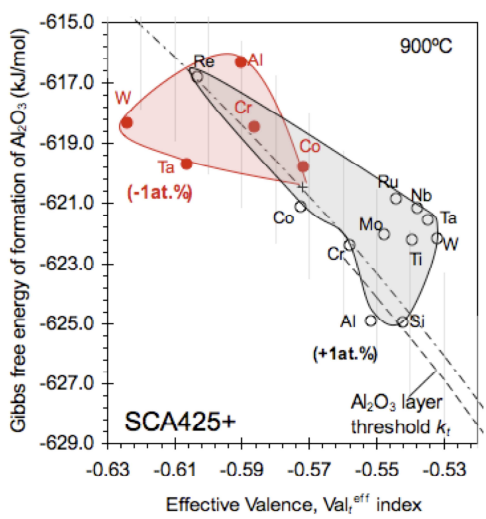

Fig.6 The effect of alloying element has on the oxidation diagram of at $900^{\circ} \mathrm{C}$

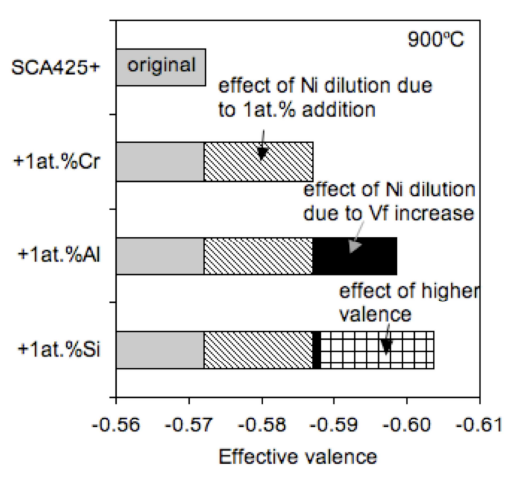

Fig.7 The effect of $\mathrm{Cr}, \mathrm{Al}$ and $\mathrm{Si}$ on the effective valence of SCA425+ alloy at $900^{\circ} \mathrm{C}$ 


\section{Acknowledgements}

The authors are grateful to Siemens Industrial Turbomachinery AB for sponsoring this work. The invaluable advice and full support of Prof. Hugh E. Evans, Dr. Mary P. Taylor, Dr. Yu-Lung Chiu,

Dr. Robert Broomfield and Mr. Peter Cranmer at the University of Birmingham is acknowledged.

\section{References}

[1] R.V. Miner and C.E. Lowell: Effects of Silicon Additions on Oxidation and Mechanical Behavior of the Nickel-Base Superalloy B-1900. (NASA, U.S. 1975).

[2] A. Sato, H. Harada, J. Ang, Y. Koizumi, T. Kobayashi, K. Kawagishi and H. Imai, in: Vol.53 of Materials for Advanced Power Engineering 2006 Proceedings of the 8th Liége Conference Part 1, edited by J. Lecomte-Beckers, M. Carton, F. Schubert, P.J. Ennis. Schriften des Forschungszentrums Jülich, Reihe Energietechnik/ Energy Technology, (2006), p.655

[3] A.C. Yeh, K. Kawagishi, H. Harada, T. Yokokawa, Y. Koizumi, T. Kobayashi, J. Ping, J. Fujioka and T. Suzuki, in: Superalloys2008, edited by R.C. Reed, K.A. Green, P. Caron, T.P. Gabb, M.G. Fahrmann, E.S. Huron, S.R. Woodard, TMS, (2008), p.619

[4] J.L. Smialek, C.A. Barrett and J.C. Schaeffer: Materials Selection and Design, Vol. 20. edited by G.E Dieter. ASM International, (1997), p.589

[5] A. Sato, Y.L. Chiu and R.C. Reed: submitted to Acta Materialia (2010)

[6] N. Birks, G.H. Meier and F.S. Pettit: Introduction to the high-temperature oxidation of metals. Cambridge University Press, (2006).

[7] N. Saunders and A.P. Miodownik: CALPHAD Calculation of Phase Diagrams -A Comprehensive Guide-. edited by R.W.Cahn. PERGAMON MATERIALS SERIES, Vol. 1. PERGAMON, (1998).

[8] O. Knacke, O. Kubaschewski and K. Hesselmann: Thermochemical properties of Inoganic substances. edited by O. Knacke, O. Kubaschewski, K. Hesselmann. Springer-Verlag Berlin, Heidelberg, (1991).

[9] N. Birks, G.H. Meier and F.S. Pettit: JOM Vol. 46 (1994), p.42

[10]R.C. Reed: The Superalloys -fundamentals and applications-. Cambridge University Press, (2006).

[11]M. Göbel, A.Rahmel and M. Schütze: Oxid. Met. Vol.39 (1993), p.231

[12]G.H. Meier, F.S. Pettit and K. Onal: Interaction of Steam/Air Mixtures With Turbine Airfoil Alloys and Coatings Final Report. US Department of Energy, Morgantown Energy Technology Center, Contract Number DE-FE21-92MC29061, (2002)

[13]K. Onal, M.C. Maris-Sida, G.H. Meier and F.S. Pettit, in: Superalloys2004 edited by K.A. Green, T.M. Pollock, H. Harada, T.E. Howson, R.C. Reed, J.J. Schirra, S. Walston. TMS, (2004), p.607

[14]K. Kawagishi, A. Sato, T. Kobayashi and H. Harada: J. Japan Inst. Metals Vol.71 (2007), p.313

[15]J.H. Chen, P.M. Rogers and J.A. Little: Oxid. Met. Vol.47 (1996), p.381

[16]B.A. Pint, J.R. Martin and L.W. Hobbs: Solid State Ionics Vol.78 (1995), p.99 